\title{
Maybe Aesop Was Right, the Tortoise Does Win: A Natural History of the Slow Reading Movement
}

\author{
W. Jason Niedermeyer (Corresponding author) \\ Willamette University, USA \\ E-mail: wniederm@willamette.edu
}

Doi:10.7575/aiac.alls.v.8n.3p.72

URL: http://dx.doi.org/10.7575/aiac.alls.v.8n.3p.72
Received: 19/04/2017

Accepted: 16/06/2017

\begin{abstract}
In the past decade, there has been a growing recognition that society's emphasis on speed and efficiency came with some costs: a loss of the ability to appreciate activities and understand their meanings. Recently, this meta-movement has made its way into the literature on literacy, causing the author to embark on an investigation into the veracity of the claims that slow reading might also mean better reading. A natural history approach was adopted for the analysis to evaluate whether there was evolutionary justification for the movement, leading to the review of relevant work in the fields of ethology, psychology, cognitive neuroscience, anthropology, sociology, linguistics, and literacy. The findings reveal an evolutionary push toward both speed and understanding, two aims that eventually come to be at odds in expert readers. It is the conclusion of the author that, from an evolutionary perspective, there may be justification for the start of a slow reading movement, but that it must be paired with practices that develop the capacity to read fast.
\end{abstract}

Keywords: Slow reading, Literacy, Reading speed, Cognition

\section{Introducing the Reader: Slow and Fast Varieties}

Ours is a shrinking planet. Not in a geographic sense, but in a temporal one. It takes less time to travel from one place to another, less time to track down long lost friends (Friedman, 2006), less time to order and receive a meal (Ritzer, 2010), and less time to find information of all sorts (Miedema, 2009). But because it seemingly takes less time to do everything, the expectation is that the average citizen will be able to do more (Ritzer, 2010). This assumption requires that greater amounts of information be encountered at higher rates - and though the mediums are becoming different in a digital age, the primary delivery device remains largely the same: alphabetic text. That the word "text" has become synonymous with the delivery of lexical information through a contraption initially developed for vocal communication - the cellular phone - is a testament to both the versatility and durability of the written word. And now, in an era of seemingly limitless information available via texts and tweets, e-mails and instant messages, blogs and Facebook posts, the pressure to glean something meaningful from any of it has meant that reading, once thought to be a leisurely process, has become an activity that is to be done quickly (Miedema, 2009).

This need for speed, having bled into all aspects of life, has spurred a backlash against what some perceive as undue haste. Beginning with the slow food movement (Honore, 2004), "the slow movement" has attracted a following in activities as varied as parenting (Gibbs, 2009), the construction of cities (Knox, 2005), and media production (Berry \& Keep, 2015). The anti-speed injunction has managed to gain a toehold in the reading community, with the executive editor of Harvard's humanities recognizing that if there were not a governor applied to people's reading rates, it would lead to the demise of graduate programs in literature (Waters, 2007). This concern likely derives from the concern that it is only through slow reading that one can truly access the intent of the author (Fletcher, 2007), allowing the reader to join the author in a literary partnership as opposed to the passive receipt of information (Mikics, 2013).

Some of the concern for the drift towards faster reading derives from what it is we are reading. The explosion of digital content at people's fingertips has meant that there are less avid book readers than there once were (Kingsley, 2010) and that we are becoming more distracted (Carr, 2011; Levine, Waite, \& Bowman, 2007). Advocates of the slow reading movement have used this shift in reading practices as a sort of rallying cry, pointing to a 2005 Kaiser Family Foundation study that demonstrated that book reading is the strongest predictor of success in college for students (Bauerlein, 2008; Mikics, 2013). Most of the arguments for slow reading, however, are of the aesthetic variety, appealing in an almost existential way to the reader that, through the very act of encountering prose slowly, one is more likely to both lose and find herself (Miedema, 2009). An argument made in this way becomes one of philosophy and culture, and these are the sorts of arguments destined to continue in perpetuity, with the two sides equally entrenched, for neither can claim the high ground because of a decided lack of any empirical basis for their perspective. Were one side to ground their argument in the natural sciences, however, a winner might be declared and a truce struck between the dueling camps full of literary tortoises and tweeting hares. This paper is an attempt to pen the stipulations of that truce. 


\section{A Methodology for Understanding the Role of the Reader}

In an attempt to critically evaluate the veracity of the claims of the slow reading movement, I decided to cast a wide net with an eye on understanding what in our natural and cultural history would provide justification for its existence. This endeavor required my beginning with evolutionarily relevant literature on social and cultural transmission-the goal of writing - as well as research on theory of mind (required to understand the author and his or her characters) and symbolic recognition. Much of this literature was cross-referenced with research on cognition in both neuroscience and psychology, particularly that which focused on the effect of reading on the brain and the mind respectively. This research was compared with the findings of anthropological research on the role of storytelling in various cultures both orally and through texts. Contemporary sociological research provided insight into the changing cultural expectations surrounding speed and literacy. These threads then led to a search into the literature on reading rates, which finally brought me back around into the place reading takes in our understanding of the nature of human language and linguistics.

\section{The Evolution of the Reader}

The human brain is not built to read. This is not to say that it fails to allow for communication, for by all counts, humans are the most social of primates (Dunbar, 1993) and among the most social animals on the planet (E. O. Wilson, 1975). Such overt sociality expresses itself in myriad forms of affiliate recognition and communication (Calude $\&$ Pagel, 2011; de Waal, 2006; Seyfarth \& Cheney, 2010). That each of these can be traced to specific loci in the brain suggests that the capacity to engage in the social transmission of ideas is an evolutionary necessity for humanity (van Schaik \& Burkart, 2011; Whiten, 2011; Whiten \& Van Schaik, 2007). What humans are not predisposed to be, however, is literate. It has taken the use and appropriation of various areas of the brain (Dehaene, 2010; Wolf, 2007) to facilitate the development of a method for transferring information not just across the space that exists between individuals but through the time that exists between generations (Changizi, 2011).

Social transmission, in general, manifests itself in humans through vocalizations. The evolutionary basis for this practice is likely an appropriation of the general purpose of audition for most species: sounds serve as signals of events (Changizi, 2011). This automatically predisposes a human to attend to an auditory stimuli's origin and explains why some have argued that the seat of language processing is actually in the reptilian brain (Lieberman, 2002). With rising pitch the product of an object approaching, the animal brain is wired to respond to this pattern of sound, a physical reality that is co-opted by language through the natural instinct to raise one's voice at the end of a question (Changizi, 2011) or during baby talk (Falk, 2010). The ability to begin linking particular sounds to specific events is seen in a wide array of taxa, and this sort of auditory comprehension is the way in which non-human animals are most like humans in regards to language (Seyfarth \& Cheney, 2010).

In other primates, this capacity may be attributable to the existence of homologs for the two areas of the brain most frequently identified as associated with language production and processing in humans, Broca's Area (Gil-da-Costa et al., 2006; Taglialatela, Russell, Schaeffer, \& Hopkins, 2008) and Wernicke's Area (Gannon, Holloway, Broadfield, \& Braun, 1998; Spocter et al., 2010). That language production is limited in non-human primates (Seyfarth and Cheney, 2010) is therefore due not to the possession of a unique region of the brain, but rather to the differences in linkages between the regions devoted to fine motor skills and language processing. For groups where the production of elaborate vocalizations is an evolutionary necessity, strong connections between these brain areas have been identified in birds (Nottebohm \& Liu, 2010; Riede \& Goller, 2010) as well as humans (Falk, 2010; F.R. Wilson, 1999). With their limited capacity for vocalization, it is unsurprising that non-human primates have come to utilize gestures to enhance communication between individuals (Pollick \& de Waal, 2007), activating the language production areas of the brain both when vocalizing and gesturing (Taglialatela, et al., 2008).

Part of the effectiveness in gestural communication in both human and non-human primates comes from their possession of mirror neurons. Located in the motor region of the brain in higher primates, mirror neurons are activated not only through action but also through the viewing of action (de Waal, 2009; Gallese, Fadiga, Fogassi, \& Rizzolatti, 1996). Their presence facilitates the sort of master and apprentice practice that is widely deployed as an effective form of social transmission in both human (Harhoff \& Kane, 1997; Lave, 1977) and non-human primates (Matsuzawa et al., 2001). As a species capable linguistic communication, however, the activation of mirror neurons can also be elicited through the art of story-telling (Gazzaniga, 2009; Gottschall, 2012). Therefore, it should come as no surprise that it is the presentation of a dramatic narrative - particularly with heroes (Ong, 1982) - that is most likely to activate the kind of thoughtful interest associated with learning (Hall, 2010; Nettle, 2005; Sharot, 2011). Because these ritualistic stories are most often delivered to large audiences (Dissanayake, 1995), it allows them to effectively transfer information throughout the group (Gottschall, 2012; Ong, 1982). It is a neurological trick charismatic leaders have been using for centuries (Sparrowe, 2005).

The use of narratives as a means to transmit information or to elicit followers would not be possible, however, without symbolic thought. Likely located in a much more distal region of the brain due to its more recent development, the ability to think in terms of symbols is considered by most to be uniquely human (Deacon, 1997; Henshilwood \& d'Errico, 2011). That no single structure has been identified with this capacity, however, suggests it may be a product of the recruitment of areas with different primary functions to work in conjunction to produce the effect (Ramachandran $\&$ Hubbard, 2001). With vertebrates from various taxa able to be both classically and operant conditioned (Kirsch, Lynn, Vigorito, \& Miller, 2004), the foundational ability of an organism to recognize patterns as they develop in a sequential fashion is likely an ancient cognitive mechanism. 
Such a capacity would be an absolute necessity to facilitate the understanding of any sort of communicative signal, be it a vocalization, a gesture, or a mark on a page or screen. For this to work in a fashion whereby the information is both being purposely provided by one individual and also by another who recognizes it is coming from a thoughtful actor requires a much higher level of cognition (Leslie, 1987). Termed a "theory of mind," the possession of this capacity has been succinctly defined as an "individual imput[ing] mental states to himself and to others" (Premack \& Woodruff, 1978 , p. 515). Viewed in this light, it has been identified that the ability to take into account another's perspective exists only in a select group of mammals - apes (Call \& Tomasello, 2008), monkeys (Kummer, Anzenberger, \& Hemelrijk, 1996), dogs (Maginnity, 2007), dolphins (Tomonaga, Uwano, Ogura, \& Saito, 2010) — and the "brainiest" group of birds, the corvids (Bugnyar \& Heinrich, 2005; Dally, Emery, \& Clayton, 2006). That this capability exists in largely unrelated groups of animals is further evidence that for fully symbolic thought to develop in humans requires the unique connection of a diffuse network of neurons scattered throughout the brain (Dehaene, 2009; Wolf, 2007).

The most impressive exhibition of symbolic thought in non-humans has been observed in chimpanzees and bonobos (commonly known as pygmy chimpanzees). Utilizing lexigrams-boards or screens with symbols to represent all manner of words (including nouns, verbs, and adjectives) - these apes are capable of complex communication that affords them the ability to describe new experiences with invented phrases (e.g. a first taste of kale led the bonobo Kanzi to describe the leafy plant as "slow lettuce") (Kluger, 2010; Lyn, Greenfield, \& Savage-Rumbaugh, 2011; E. S. Savage-Rumbaugh et al., 1993; S. Savage-Rumbaugh, Sevcik, \& Hopkins, 1988). That such boards are used by humans who have lost their capacity to form words but not their ability to communicate symbolically (Sacks, 2010) further suggests that the necessity of symbolic recognition to a reading brain exists, at the very least, in humans' closest evolutionary relatives (Lyn, Greenfield, Savage-Rumbaugh, Gillespie-Lynch, \& Hopkins, 2010).

What may separate the human brain in a way that has made it possible for it not only to recognize symbols but also to generate them is the development of the hand. Millions of years in the making, the modern human hand possesses a dexterity for the manipulation of tools that does not exist in chimpanzees (F. R. Wilson, 1999). Without a fully opposable thumb, chimpanzees are unable to hold a utensil in a fashion that would allow for the generation of even the most rudimentary of symbols associated with the earliest writing systems (McGrew, 1992; F. R. Wilson, 1999; Wolf, 2007).

Even as the physiology necessary to develop symbolic representation of thoughts on a substrate became possible in one of the predecessors of humans_-perhaps Homo erectus (Gould, 1992; Shreeve, 1995; F. R. Wilson, 1999) - the use of physically constructed symbols of any sort (i.e. cave art, beading on necklaces, tokens for trading) dates back, at the earliest, to somewhere between 44 and 80 thousand years ago (Dutton, 2009). It has been suggested that the emergence of such overt use of symbolism was the outward manifestation of the birth of the modern human both cognitively and physically (Henshilwood \& d'Errico, 2011; Henshilwood \& Marean, 2003). And yet, even as the human form was finally prepared to read and write, the first known system of symbols, likely used for accounting, did not come into existence until 10,000 years ago in western Asia (Wolf, 2007). It was not followed by a true system of writing for another 4500 years when the Sumerians developed cuneiform (Michalowski, 1996). The delay of nearly 75,000 years from the development of the necessary cognitive capacity for reading and the creation of something to read serves as an ontogenetic portent of the primary necessity for the optimal utilization of the reading brain - time.

\section{The Automatic Reader}

The time it took for humans that possessed a brain with the potential for reading to develop a reading brain is likely because neural circuitry was not the only thing that needed to be changed - so did their perception of themselves and the world. In characteristically oral societies, knowledge acquired through experience that might be of help to otherseffectively known as wisdom (Hall, 2010) - is transmitted orally through proverbs and other mnemonic aids (Ong, 1982; Reagan, 2005; D. S. Wilson, 2007) This produces the "great art of conversation," whereby these nuggets of knowledge "form the substance of thought itself" (Ong, 1982, p. 35). Such transmission patterns channel an individual's thoughts towards the group with such veracity that, when asked a series of personal questions by the Russian psychologist A.R. Luria in the 1930s, respondents provided answers that would seem inconceivable to the literate mind (in D.S. Wilson, 2007, p. 225):

Question: "What sort of person are you? What's your character like? What are your good qualities and shortcomings? How would you describe yourself?"

Answer: "I came here from Uch-Kurgan, I was very poor, and now I'm married and have children."

Question: "People are different-calm, hot-tempered, or sometimes their memory is poor. What do you think of yourself?"

Answer: "We behave well—if we were bad people, no one would respect us."

Answer [another individual]: "What can I say about my own heart? How can I talk about my character? Ask others; they can tell you about me. I myself can't say anything."

Such answers betray the need for group-oriented, practical thoughts when an individual resides in a society that must transfer all information in an oral-and social-fashion. This mindset may explain why cultures across the globe that rely heavily on orality unite people with proverbs used to transfer knowledge and solve disputes (Reagan, 2005). The aim, as described by the Native American Gail High Pine, “ ... is not ... to preserve our traditions, [but] ... to allow our traditions to preserve us" (quoted in Hampton, 1995, p. 22). 
In primarily oral societies it is not only self-perception that is affected-so is one's general perception of the world. When Luria (1976) presented his research subjects with objects and asked them to identify the shapes they saw, the answers he received were those like "plate" (i.e. circle) and "mirror" (i.e. oval). These perceptions of the objects suggest the subjects identified the objects based on their potential for having a concrete purpose as opposed to deserving some abstract categorization. There is a neurological basis for this behavior, for in order for the brain to recognize abstract shapes - like letters or drawings (Cohn, Paczynski, Jackendoff, Holcomb, \& Kuperberg, 2012) - it must appropriate a cortical region developed for object and face recognition (Dehaene, 2010). As an individual becomes increasingly literate, there is a correlated decrease in his capacity to recognize faces (Cantlon, Pinel, Dehaene, \& Pelphrey, 2011), suggesting there is competition for the neural space necessary to allow for visually symbolic processing. Therefore, for individuals in a non-literate society, the neural modules for shape recognition and identification in the left hemisphere are devoted to the concrete and not the abstract, whereas in literate individuals some of these modules are appropriated for letter identification, creating the brain's "letterbox" (Dehaene, 2010). The recognition that the left hemisphere is typically associated with processing of the familiar visual inputs while the right is associated with the processing of novel ones (Gazzaniga, 2009) suggests that thinking in abstractions like symbols and letters becomes familiar in literate individuals but not in non-readers.

That neurons do not exist but must be appropriated for reading is indicative of the neural reorganization required for one to be able to read. Though visual in its presentation, writing, as a form of communication, must access the same areas of the brain used for language processing and production (Devauchelle, Oppenheim, Rizzi, Dehaene, \& Pallier, 2009), allowing one to have "a conversation with the deceased" by "listen[ing] to the dead with [one's] eyes" (Francisco de Quevedo in Dehaene, 2010, p. 20). Such conversations require not only access to the phonological regions of the brain but also an innate understanding of syntax (Pinker, 2007). Syntax is most often (and almost exclusively) thought of in regards to linguistics, but its processing is derived from areas of the brain devoted to sensory motor function (Wolf, 2007), through which a "syntax" for tool use was developed and refined over millions of years (Malafouris, 2013; F.R. Wilson, 1999).

An even more basal region of the brain, the limbic system, also becomes active when reading. Associated with emotions, the activation of the limbic system allows for feelings in the reader to be elicited through an encounter with what are nothing more than lines on a page to the non-literate individual (Wolf, 2007).

Through the integrated activation of these varied and largely neurologically disparate regions of the brain, the reader is able to, with time, develop not only a greater breadth of semantic understanding (Ditman, Holcomb, \& Kuperberg, 2007; Holcomb, 1988), but also achieve some level of automaticity when reading (Wolf, 2007). Such neural reorganization occurs both in children learning to read as well as adults (Dehaene, 2010), suggesting that regardless of age, one can develop into an expert reader, one capable of processing and deriving meaning from each and every word on a page in less than 500 milliseconds (Wolf, 2007). The capacity to read quickly — on average, 250 words a minuteis therefore an ability most people in developed societies will acquire in their lifetimes, most likely at an early age (Love, 2012). Therefore, with the nearly universal possibility of fast reading in literate societies, the question becomes not if individuals can engage in a quick read but if they should.

\section{The Understanding Reader}

With more and more texts available in general and in digital form in particular, the inclination for many people is to read more - and more quickly (Miedema, 2009). From a biological perspective, this phenomena may be a manifestation of what ethologists consider "peak shift," or a disproportionate attraction to the "super-normal" stimulus (Staddon, 1975; Tinbergen, 1953). Signals, be they vocal or gestural, are particularly amenable to "peak shifting" by the signaler, which allows for the overt manipulation of the receiver (Arak \& Enquist, 1993), and it is thought this innate psychological response is frequently elicited, with intent, by abstract artists (Ramachandran \& Hirstein, 1999). Such a biological drive may partially explain the "more is better" sense of reading that has emerged in the digital age, though there is most likely a cultural component as well. The industrial movement brought rise to an overwhelming desire for efficiency in the work-place, an expectation that began to travel home with the workers (Ritzer, 2010). Possessing the overwhelming desire for efficiency in all aspects of life seems rational. For the literate individual, this compulsion would inevitably mean the more words (and more ideas) encountered for each minute spent reading, the better. Such hyper-rationality, however, often leads to irrationality (Ritzer, 2010), and for the reader, this comes with cognitive consequences.

When the words written on a page (or a screen) are first encountered, the brain moves through an evaluation process in order to derive as much meaning from the text as possible before moving onto the next word (Wolf, 2007). The last stage of this processing is a semantic one, whereby the reader evaluates the word in the context, not only in the work before her but also in the context of her reading (Love, 2012) and life's experience (Dehaene, 2009; Wolf, 2007). This may require the reader to reread a word or a phrase, practices that have been shown to have a positive impact on textual recall (Hyonua \& Nurminen, 2006). Semantic understanding of prose may also be greatly impacted by the changing of a single word, which can lead to changes in response to an entire piece of literature (Gottschall \& Wilson, 2005). It therefore becomes quite consequential to find that "speed readers" (those reading 600-700 words per minute) do so by skipping regions of the text, and it explains why people who encounter text at that rate fail with regard to understanding the details of the text (Love, 2012). It would seem that by the very act of reading fast, the reader is depriving herself of the deepest understanding permitted by even the most automatic of reading brains. 
Outside of its application to literacy, semantic understanding sits at the middle ground between people's outward sensorial perceptions and episodic memories with related contexts. Residing in this position means that developing a semantic understanding of a situation requires a reconciliation of the physical reality of what they are experiencing with their mental representation of the experience (Clark, 2016). For these two disparate forms of understanding the world to become connected and produce increasingly accurate predictions requires increased exposure to similar situations. While this necessity can be achieved simply through the act of living, it is best done through play (Brown \& Vaughan, 2009). Play's success as a learning method is derivative of the fact that it necessarily transpires in a low stress environment. When knowledge is utilized in the absence of stress, it not only allows for the development and strengthening of neural linkages and pathways between disparate regions of the brain (Brown \& Vaughan, 2009), it precipitates the use of the most distal, and human, region of the brain, the pre-frontal cortex (Gazzaniga, 2009). This allows an individual to move "beyond modularity" (Karmiloff-Smith, 1992), and engage in the kind of cognitive gestalt unique to humans (Dehaene, 2009).

In stressful situations, however, such cognitive processes are stifled and can impede learning (Sapolsky, 1996). Because much of quick reading is the product of the stress induced by a world moving at an increasingly fast pace (Miedema, 2009), the effect on the reading brain is largely going to be dependent on the stage of the reader in his development. For the individual who is learning to read, the stress induced by an undue emphasis on speed may arrest the development of the neuronal connections requisite for becoming an expert reader (Wolf, 2007). For the individual who is reading to learn and for whom the practice of identifying words has become automatic, reading under duress is likely to precipitate the reader only seeking out information that is familiar, effectively selecting a data stream that supports his assumptions (Clark 2016), justifying the continued use of his own time-tested heuristics (Todd, 2000). Such an outcome would prevent the sort of "conversation" with the author that not only is indicative of the cognitive process of reading (Dehaene, 2010), but also allows a reader to be transported by the author and her characters (Gerrig \& Rapp, 2004). These processes are what allow for the semantic and contextual understanding that serves as the final tier of processing for the automatic reader.

\section{The Reflective Reader}

Even as readers finish (or not) the process of generating a semantic understanding of the words on the page, in order to more fully contextualize what has been put forth by the author, they must begin to reflect on the entirety of the piece in respect to her own life. Such a process allows learners to use the plight of characters in a different space and time (e.g. the Victorian England of Pride and Prejudice) to understand their own situation (e.g. the integration of American schools) (Coles, 1989). The professor of comparative literature, Eugene Eoyang (2012), has concluded such an activity is critical because "Great literature expands our knowledge not only of others, but of unsuspected aspects of our own character as well” (p. 6).

As readers age, they have an ever growing stable of experiences from which to draw, and their response to a piece is likely to change over time (Wolf, 2007). Such reflection forces readers to both categorize and evaluate based on her acquired knowledge and to identify what they do not know and may still be able learn from the piece, an ability that takes much of a lifetime to develop (Fischer, Dawson, \& Schnepps, 2010). This self-recognition of ignorance was considered by Socrates to be the hallmark of a wise man (Hall, 2010), and in order for it to be achieved in a reader requires not only a cursory experiencing and appraisal of the work, but also the time necessary for reappraisal (Gazzaniga, 2009).

The inclination towards moving quickly through text, thereby preventing the thought necessary to derive real meaning from the work, lends credence to the fear Socrates possessed about the use of the written word: namely, a superficiality of understanding (Wolf, 2007). When information is transmitted through dialogue, it provides the listener with the opportunity to question the speaker in the hope of deriving meaning from what might otherwise seem a series of disconnected bits of information (Noddings, 2010). In the absence of an author to physically question, it seems that Socrates considered written communication a sort of "'dead discourse," whereas "“living speech" represented dynamic entities - full of meanings, sounds, melody, stress, intonation, and rhythms - ready to be uncovered layer by layer through examination and dialogue" (Wolf, 2007, p. 73). The ancient philosopher, had he been privy to the neurological activity of reading, would likely have been afraid that the reader would come to ignore the internal dialogue that lies at the heart of the practice of reading (Dehaene, 2010). But it is internal dialogue that allows for a more complete understanding of an author's aims (Fletcher, 2007), the reader's own persona (Eoyang, 2012), and the world at large (Gottschall, 2012). And while he may have been assuaged to learn of the use of various brain regions - many of which are identical to those used when speaking - to generate meaning from text, he would likely have been fearful of the explosion of written media and of the expectation of literary alacrity in contemporary society. Without taking the time to question the author about the viability of the information and his motives for delivering it, Socrates would be concerned that the reader might not question the veracity of the information (Wolf, 2007). These concerns are shared by the elders of the Coast Salish tribe, who think it is “... the responsibility of the learner to seek out and question the Elders" (Archibald, 2008, p. 44), and that the believability of the storyteller is ascertained through interaction with him or her.

A limited understanding not only of the text but the subtext provided by the author when one is reading quickly may be as much a product of an inability to process the information from an informational standpoint as from an emotional one. Considering that the primary aim of a work of dramatic fiction is to develop conflicted emotions within the reader (Nettle, 2005), the more time readers commit to wrestling with each of the character's emotions, the more likely they 
are to activate a naturally empathetic response (de Waal, 2009). Therefore, by moving quickly through a piece, the reader is unintentionally limiting his capacity to take others' perspectives, a practice associated with wisdom (Hall, 2010) and caring (Noddings, 2010). Socrates would likely identify this as proof of his point that the dissemination of information through text is inferior to that through speech-but his claim only stands up if the reader makes the decision to limit his deployment of the internal conversation and other-perspective taking by reading quickly. Through the process of reading slowly, the reader retains the ability to empathize with others and reflect on the origins of that empathy, to take another's perspective and identify his or her emotional conflicts, and to envision and predict potential outcomes. These abilities are most succinctly activated through the process of reading (Dehaene, 2009). It would seem that by reading quickly - thought by some to represent the zenith of academic abilities (Fletcher, 2007; Miedema, 2009) - the reader, though using a uniquely human capacity, is depriving himself the use of a more important—and equally unique - one.

\section{The Truth (and Truce) about Reading Speed}

As the one animal capable of not only reading but also reading quickly, the question becomes the proverbial "just because one can, does that mean one should?" As demonstrated above, the act of reading quickly deprives the reader of evaluative opportunities by stifling many higher-level cognitive processes. That alone, however, in no way discredits fast reading in every context. By increasing one's reading rate, more text is encountered in a single sitting, providing a greater opportunity to identify the information one seeks, and in some circumstances, reading rate can be a proxy for overall comprehension of a text (Eason, Sabatini, Goldberg, \& Cutting, 2013). In many ways, this mirrors the evolutionary use for the neurons appropriated for literacy, those of facial recognition (Dehaene, 2010). In the mind, the act of looking for a loved one in a crowd is akin to searching the sports section for a particular score, or seeking one last citation for a graduate school paper. Such searching of text is only possible through the development of reading automaticity (Wolf, 2007). The pattern recognition associated with automaticity allows for more coherent comprehension of text (Eason, Sabatini, Goldberg, \& Cutting, 2013), just as situational familiarity allows for a more rapid physical response (Clark, 2016). Reading quickly also allows more text to stay in working memory and it can, ironically, prevent distraction (Love, 2012). Therefore, though rapidly reading limits the brain's ability to develop a complete semantic and contextual understanding of the text, there are many cases when this is not necessary.

With fast and slow reading both having a place in modern society, the cognitive neuroscientist might ask, which represents the pinnacle of human cognition, fast or slow reading? That automatic number (Dehaene, 2009), letter (Srihasam, Mandeville, Morocz, Sullivan, \& Livingstone, 2012) and word recognition (Grainger, Dufau, Montant, Ziegler, \& Fagot, 2012) have been demonstrated in a variety of higher primates suggests that the ability to develop automaticity is more ancient than the ability to synthesize information and create predictions about the future for both ourselves and the characters that exist in our imaginations (Dehaene, 2009). If this is the case, then it would seem that the informational absorption that comes from a slow read is the greater exhibition of a truly unique human ability.

Symbolic pattern recognition, however, is not reading - reading is a process, and a difficult one at that. It takes years to master and should be celebrated when it is accomplished. As students move from learning to read to reading to learn, they can say they have become experts (Wolf, 2007). In some cultures, with regular spelling rules (e.g. Italian), this process is achieved early; others (e.g. English) take much longer; still others (e.g. Chinese) require students to learn characters into their teenage years to be able to access the information in a newspaper (Dehaene, 2009). It is no wonder that people, when given the chance, would speed up their reading. When the text that is encountered is predictable, readers speed up and when it is tough, they slow down (Love, 2012). If they get bored (because it is too predictable or too difficult), they allow themselves to be distracted, which is easy in this digital age (Mikics, 2013). The practice of seeking novel inputs is how we garner the information we use to make predictions about the world (Clark, 2016); why should it not be applied to reading?

Perhaps it should. But if it is, what do we lose? Do we lose our capacity to tease out the author's intent? Do we lose the ability to see how characters and situations different from our own on the surface may be instructive for understanding our pasts, acting in our present, and shaping our future? We probably do.

The solution, it seems, requires a balanced approach. Early in their reading lives, students need to be exposed to written words only with familiar graphemes and phonemes, slowly acquiring the components of lexical language bit by bit until their understanding of their language is complete (Dehaene, 2009). As students become automatic readers, they will become understanding readers through the exposure to pieces of varying type, length, and difficulty (Wolf, 2007). The nearly unfettered access to content provided by the internet makes this step easier than it has ever been, which is why it is difficult to imagine that it is at this point that the reader must slow down. Thankfully, this need has been recognized by educators, with "close reading" (a proxy for slow reading) a focal practice identified in the Common Core State Standards (Hinchman \& Moore, 2013). Running counter to what often happens with standards, there has been a recognition that the definition of this practice, and its function, differs based on discipline (Shanahan, Shanahan, \& Misischia, 2011), providing educators with hope that they will be granted the latitude to experiment with methodologies necessary to turn their students into reflective readers (Hinchman \& Moore, 2013).

It is too early to tell if this emphasis on slowing students down so they can do close reading will truly change education or simply become another formalized practice that further industrializes pedagogy. What can be said is, should readers be seeking nothing more than a confirmation of their world view, they are likely to get more out of reading with a higher rate of consumption. But should they desire "a conversation with the deceased" and to feel with the author and characters, they must proceed slowly and with caution. For whether they know it or not, we are very young in our 
development as a literary species. There is still much left to examine, and as "Socrates said "the unexamined life is not worth living.' To live life without studying literature is to leave our lives unexamined" (Eoyang, 2012, p. 11). By taking their time and absorbing as much as they can from meaningful works, readers are likely to get the most they can out of the experience. So while the hare may yet win the race, the tortoise will win the prize: a greater understanding of the world through slow reading.

\section{References}

Arak, A., \& Enquist, M. (1993). Hidden preferences and the evolution of signals. Philosophical Transactions of the Royal Society of London. Series B: Biological Sciences, 340(1292), 207-213.

Archibald, J. A. (2008). Indigenous storywork: Educating the heart, mind, body, and spirit. Vancouver: UBC press.

Bauerlein, M. (2008). The dumbest generation: How the digital age stupefies young Americans and jeopardizes our future (or, don't trust anyone under 30). New York: Penguin.

Berry, M., \& Keep, D. (2015). Auratic presence through slow media. Altitude: A Journal of Emerging Humanities Work, 13 (Special Issue: Slow Media).

Brown, S. L., \& Vaughan, C. C. (2009). Play: How it shapes the brain, opens the imagination, and invigorates the soul. New York: Avery Pub Group.

Bugnyar, T., \& Heinrich, B. (2005). Ravens, Corvus corax, differentiate between knowledgeable and ignorant competitors. Proceedings of the Royal Society B: Biological Sciences, 272(1573), 1641-1646.

Call, J., \& Tomasello, M. (2008). Does the chimpanzee have a theory of mind? 30 years later. Trends in cognitive sciences, 12(5), 187-192.

Calude, A. S., \& Pagel, M. (2011). How do we use language? Shared patterns in the frequency of word use across 17 world languages. Philosophical Transactions of the Royal Society B: Biological Sciences, 366(1567), 1101-1107.

Cantlon, J. F., Pinel, P., Dehaene, S., \& Pelphrey, K. A. (2011). Cortical representations of symbols, objects, and faces are pruned back during early childhood. Cerebral Cortex, 21(1), 191-199.

Carr, N. (2011). The shallows: What the internet is doing to our brains. New York: WW Norton \& Company.

Clark, A. (2016). Surfing uncertainty: Prediction, action, and the embodied mind. Oxford: Oxford

University Press.

Cohn, N., Paczynski, M., Jackendoff, R., Holcomb, P. J., \& Kuperberg, G. R. (2012). (Pea) nuts and bolts of visual narrative: Structure and meaning in sequential image comprehension. Cognitive Psychology, 65(1), 1-38.

Coles, R. The call of stories: Teaching and the moral imagination. (1989). Boston: Houghton Mifflin Company.

Dally, J. M., Emery, N. J., \& Clayton, N. S. (2006). Food-caching western scrub-jays keep track of who was watching when. Science, 312(5780), 1662-1665.

de Waal, F. (2006). Our inner ape: A Leading primatologist explains why we are who we are. New York: Riverhead Books.

de Waal, F. (2009). The age of empathy. New York: Harmony.

Deacon, T. W. (1997). The symbolic species: The co-evolution of language and the brain. New York: WW Norton \& Company.

Dehaene, S. (2009). Reading in the brain: The science and evolution of a human invention. New York: Viking Press.

Dehaene, S. (2010). The massive impact of literacy on the brain and its consequences for education. Human Neuroplasticity and Education, 27, 19-32.

Devauchelle, A. D., Oppenheim, C., Rizzi, L., Dehaene, S., \& Pallier, C. (2009). Sentence syntax and content in the human temporal lobe: an fMRI adaptation study in auditory and visual modalities. Journal of Cognitive Neuroscience, 21(5), 1000-1012.

Dissanayake, E. (1995). Homo aestheticus: Where art comes from and why. Seattle: University of Washington Press.

Ditman, T., Holcomb, P. J., \& Kuperberg, G. R. (2007). The contributions of lexico-semantic and discourse information to the resolution of ambiguous categorical anaphors. Language and Cognitive Processes, 22(6), 793-827.

Dunbar, R. I. M. (1993). Coevolution of neocortical size, group size and language in humans. Behavioral and Brain Sciences, 16(4), 681-693.

Dutton, D. (2009). The art instinct: Beauty, pleasure, \& human evolution. Oxford: Oxford University Press.

Eason, S. H., Sabatini, J., Goldberg, L., Bruce, K., \& Cutting, L. E. (2013). Examining the relationship between word reading efficiency and oral reading rate in predicting comprehension among different types of readers. Scientific Studies of Reading, 17(3), 199-223.

Eoyang, E. (2012). The promise and premise of creativity: Why comparative literature matters. New York: Bloomsbury Academic. 
Falk, D. (2010). Finding our tongues: Mothers, infants and the origins of language. New York: Basic Books.

Fischer, K. W., Dawson, T. L., \& Schnepps, M. (2010). Plasticity in learning pathways: Assessments that capture and facilitate learning. Human Neuroplasticity and Education, 27, 100.

Fletcher, L. R. (2007). Slow reading: The affirmation of authorial intent. http://www.freelance-academy.org-www.freelance-academy.org/slowread.pdf

Friedman, T. L. (2006). The world is flat: A brief history of the twenty-first century. New York: Farrar Straus \& Giroux. Gallese, V., Fadiga, L., Fogassi, L., \& Rizzolatti, G. (1996). Action recognition in the premotor cortex. Brain, 119(2), 593-609.

Gannon, P. J., Holloway, R. L., Broadfield, D. C., \& Braun, A. R. (1998). Asymmetry of chimpanzee planum temporale: humanlike pattern of Wernicke's brain language area homolog. Science, 279(5348), 220-222.

Gazzaniga, M. S. (2009). Human: The science behind what makes us unique. New York: HarperCollins.

Gerrig, R. J., \& Rapp, D. N. (2004). Psychological processes underlying literary impact. Poetics Today, 25 (2), $265-281$.

Gibbs, N. (2009). The growing backlash against overparenting. Time Magazine, 1940395-1940391.

Gil-da-Costa, R., Martin, A., Lopes, M. A., Munoz, M., Fritz, J. B., \& Braun, A. R. (2006). Species-specific calls activate homologs of Broca's and Wernicke's areas in the macaque. Nature Neuroscience, 9(8), 1064-1070.

Gottschall, J., \& Wilson, D. S. (2005). Introduction: Literature-a last frontier in human Evolutionary studies. In J. Gottschall \& D. S. Wilson (Eds.), The literary animal: Evolution and the nature of narrative. Evanston: Northwestern University Press.

Gottschall, J. (2012). The storytelling animal: How stories make us human. New York: Houghton Mifflin Harcourt.

Gould, S. J. (1992). The panda's thumb: More reflections in natural history. New York: WW Norton \& company.

Grainger, J., Dufau, S., Montant, M., Ziegler, J. C., \& Fagot, J. (2012). Orthographic processing in baboons (Papio papio). Science, 336(6078), 245-248.

Hall, S. S. (2010). Wisdom: From philosophy to neuroscience. New York: Knopf.

Hampton, E. (1995). Towards a redefinition of Indian education. First Nations education in Canada: The circle unfolds, 5-46. Vancouver: UBC Press.

Harhoff, D., \& Kane, T. J. (1997). Is the German apprenticeship system a panacea for the US labor market? Journal of Population Economics, 10(2), 171-196.

Henshilwood, C. S., \& d'Errico, F. (2011). Homo symbolicus: The dawn of language, imagination and spirituality. London: John Benjamins Publishing Company.

Henshilwood, C. S., \& Marean, C. W. (2003). The origin of modern human behavior. Current Anthropology, 44(5), 627-651.

Hinchman, K. A., \& Moore, D. W. (2013). Close reading: A cautionary interpretation. Journal of Adolescent \& Adult Literacy, 56(6), 441-450.

Holcomb, P. J. (1988). Automatic and attentional processing: An event-related brain potential analysis of semantic priming. Brain and Language, 35(1), 66-85.

Honore, C. (2004). In praise of slow: How a worldwide movement is challenging the cult of speed. Toronto: Vintage Canada.

Hyonua, J., \& Nurminen, A. M. (2006). Do adult readers know how they read? Evidence from eye movement patterns and verbal reports. British Journal of Psychology, 97(1), 31-50.

Karmiloff-Smith, A. (1992). Beyond modularity: A developmental perspective on cognitive science. Cambridge, MA: MIT Press.

Kingsley, P. (2010). The art of slow reading. The Guardian, 15.

Kirsch, I., Lynn, S. J., Vigorito, M., \& Miller, R. R. (2004). The role of cognition in classical and operant conditioning. Journal of Clinical Psychology, 60(4), 369-392.

Kluger, J. (2010). Inside the minds of animals. Time International (South Pacific Edition), 176(7), 26-33.

Knox, P. L. (2005). Creating ordinary places: Slow cities in a fast world. Journal of Urban Design, 10(1), 1-11.

Kummer, H., Anzenberger, G., \& Hemelrijk, C. K. (1996). Hiding and perspective taking in long-tailed macaques (Macaca fascicularis). Journal of Comparative Psychology; Journal of Comparative Psychology, 110(1), 97-102.

Lave, J. (1977). Cognitive consequences of traditional apprenticeship training in West Africa. Anthropology \& Education Quarterly, 8(3), 177-180.

Leslie, A. M. (1987). Pretense and representation: The origins of" theory of mind.". Psychological Review, 94(4), 412426.

Levine, L. E., Waite, B. M., \& Bowman, L. L. (2007). Electronic media use, reading, and academic distractibility in college youth. Cyber Psychology \& Behavior, 10(4), 560-566. 
Lieberman, P. (2002). Human language and our reptilian brain: the subcortical bases of speech, syntax, and thought. Cambridge: Harvard University Press.

Love, J. (2012). Reading fast and slow. The American Scholar, 81(2), 64-73.

Lyn, H., Greenfield, P. M., \& Savage-Rumbaugh, E. S. (2011). Semiotic combinations in Pan: A comparison of communication in a chimpanzee and two bonobos. First Language, 31(3), 300-325.

Lyn, H., Greenfield, P. M., Savage-Rumbaugh, S., Gillespie-Lynch, K., \& Hopkins, W. D. (2010). Nonhuman primates do declare! A comparison of declarative symbol and gesture use in two children, two bonobos, and a chimpanzee. Language \& Communication 31(1), 63-74.

Maginnity, M. (2007). Perspective Taking and Knowledge Attribution in the Domestic Dog (Canis familiaris): A Canine Theory of Mind? Master's Thesis, University of Canterbury.

Malafouris, L. (2013). How things shape the mind. Boston: MIT Press.

Matsuzawa, T., Biro, D., Humle, T., Inoue-Nakamura, N., Tonooka, R., \& Yamakoshi, G. (2008). Emergence of culture in wild chimpanzees: Education by master-apprenticeship. In Primate origins of human cognition and behavior (pp. 557-574). Tokyo: Springer.

McGrew, W. C. (1992). Chimpanzee material culture: Implications for human evolution. Cambridge: Cambridge University Press.

Michalowski, P. (1996). Mesopotamian cuneiform: Origin. In P. Daniels \& W. Bright (Eds.), The world's writing systems (pp. 33-36). New York: Oxford University Press.

Miedema, J. (2009). Slow reading. Duluth, MN: Litwin Books Llc.

Mikics, D. (2013). Slow reading in a hurried age. Cambridge: Harvard University Press.

Nettle, D. (2005). What happens in Hamlet? Exploring the psychological foundations of drama. In J. Gottschall \& D. S. Wilson (Eds.), The literary animal: Evolution and the nature of narrative (pp. 56-75). Evanston, IL: Northwestern University Press.

Noddings, N. (2012). Philosophy of education ( $3^{\text {rd }}$ edition). Philadelphia: Westview Press.

Nottebohm, F., \& Liu, W. C. (2010). The origins of vocal learning: New sounds, new circuits, new cells. Brain and Language, 115(1), 3-17.

Ong, W. J. (1982). Orality and literacy: The technologizing of the word. New York: Methuen.

Pinker, S. (2007). The stuff of thought: Language as a window into human nature. New York: Viking Press.

Pollick, A. S., \& de Waal, F. (2007). Ape gestures and language evolution. Proceedings of the National Academy of Sciences, 104(19), 8184-8189.

Ramachandran, V. S., \& Hirstein, W. (1999). The science of art: A neurological theory of aesthetic experience. Journal of Consciousness Studies, 6(6-7), 6-7.

Ramachandran, V. S., \& Hubbard, E. M. (2001). Synaesthesia--a window into perception, thought and language. Journal of Consciousness Studies, 8(12), 3-34.

Reagan, T. (2005). Non-Western educational traditions: Indigenous approaches to educational thought and practice ( $3^{\text {rd }}$ edition). Mahwah, NJ: Lawrence Erlbaum Associates.

Riede, T., \& Goller, F. (2010). Peripheral mechanisms for vocal production in birds-differences and similarities to human speech and singing. Brain and Language, 115(1), 69-80.

Ritzer, G. (2010). The McDonaldization of society 6. New York: Sage Publications, Inc.

Sacks, O. (2010). The mind's eye. New York: Knopf.

Sapolsky, R. M. (1996). Why stress is bad for your brain. Science, 273(5276), 749-751.

Savage-Rumbaugh, E. S., Murphy, J., Sevcik, R. A., Brakke, K. E., Williams, S. L., Rumbaugh, D. M., et al. (1993). Language comprehension in ape and child. Monographs of the Society for Research in Child Development.

Savage-Rumbaugh, S., Sevcik, R. A., \& Hopkins, W. D. (1988). Symbolic cross-modal transfer in two species of chimpanzees. Child Development, 617-625.

Seyfarth, R. M., \& Cheney, D. L. (2010). Production, usage, and comprehension in animal vocalizations. Brain and Language, 115(1), 92-100.

Shanahan, C., Shanahan, T., \& Misischia, C. (2011). Analysis of expert readers in three disciplines: History, mathematics, and chemistry. Journal of Literacy Research, 43(4), 393-429.

Sharot, T. (2011). The optimism bias. New York: Pantheon.

Shreeve, J. (1995). The Neandertal enigma: Solving the mystery of modern human origins. New York: Morrow.

Sparrowe, R. T. (2005). Authentic leadership and the narrative self. The Leadership Quarterly, 16(3), 419-439. 
Spocter, M. A., Hopkins, W. D., Garrison, A. R., Bauernfeind, A. L., Stimpson, C. D., Hof, P. R., et al. (2010). Wernicke's area homologue in chimpanzees (Pan troglodytes) and its relation to the appearance of modern human language. Proceedings of the Royal Society B: Biological Sciences, 277(1691), 2165.

Srihasam, K., Mandeville, J. B., Morocz, I. A., Sullivan, K. J., \& Livingstone, M. S. (2012). Behavioral and anatomical consequences of early versus late symbol training in macaques. Neuron, 73(3), 608-619.

Staddon, J. (1975). A note on the evolutionary significance of" supernormal" stimuli. American Naturalist, 541-545.

Taglialatela, J. P., Russell, J. L., Schaeffer, J. A., \& Hopkins, W. D. (2008). Communicative signaling activates Broca's' homolog in chimpanzees. Current Biology, 18(5), 343-348.

Tinbergen, N. (1953). The herring gull's world. New York: Harper Collins.

Todd, P. M. (2000). The ecological rationality of mechanisms evolved to make up minds. American Behavioral Scientist, 43(6), 940.

Tomonaga, M., Uwano, Y., Ogura, S., \& Saito, T. (2010). Bottlenose dolphins' (Tursiops truncatus) Theory of mind as demonstrated by responses to their trainers' attentional states. International Journal of Comparative Psychology, 23, 386-400.

van Schaik, C. P., \& Burkart, J. M. (2011). Social learning and evolution: The cultural intelligence hypothesis. Philosophical Transactions of the Royal Society B: Biological Sciences, 366(1567), 1008-1016.

Whiten, A. (2011). The scope of culture in chimpanzees, humans and ancestral apes. Philosophical Transactions of the Royal Society B: Biological Sciences, 366(1567), 997-1007.

Whiten, A., \& Van Schaik, C. P. (2007). The evolution of animal "cultures" and social intelligence. Philosophical Transactions of the Royal Society B: Biological Sciences, 362(1480), 603-620.

Wilson, D. S. (2007). Evolution for everyone: How Darwin's theory can change the way we think about our lives. Toronto: Random House of Canada.

Wilson, E. O. (1975). Sociobiology: The new synthesis. Cambridge: Harvard University Press.

Wilson, F. R. (1999). The hand: How its use shapes the brain, language, and human culture. New York: Vintage.

Wolf, M. (2007). Proust and the squid: The story and science of the reading brain. New York: Harper Perennial. 